\title{
Reporting microvascular changes in nail fold capillaroscopy: A narrative review
}

\author{
Alireza Rajaei ${ }^{1}$, Pooneh Dehghan ${ }^{2 *}$ and Parisa Delkash ${ }^{3}$ \\ ${ }^{I}$ Assistant Professor of Rheumatology, Loghman Rheumatology Department, Shahid Beheshti University of Medical Sciences, \\ Tehran, Iran, ${ }^{2}$ Assistant Professor of Radiology, Taleghani Hospital Research Development Unit, Department of Radiology, Shahid \\ Beheshti University of Medical Sciences, Tehran, Iran, ${ }^{3}$ Rheumatology Fellow, Loghman Hospital, Shahid Beheshti University of \\ Medical Sciences, Tehran, Iran
}

\begin{abstract}
Nailfold capillaroscopy (NFC) is a useful and noninvasive procedure for evaluating patients with signs and symptoms of microvascular disturbances such as Raynaud's phenomenon, either primary or secondary, with the ability to differentiate between the two. It is widely used for the diagnosis of systemic sclerosis (SSc), and the quantitative nature of the NFC report allows the monitoring of vascular changes in these patients and predicts their prognosis during follow-up visits. Five types of abnormal findings are reported with nailfold capillaroscopy (NFC), each having a specific definition and significance. The main goal of this article is to give a comprehensive review of the most widely accepted method of performing and reporting this procedure.
\end{abstract}

Keywords: Nailfold Capillaroscopy, Raynaud's disease, Scleroderma, Systemic sclerosis.

\section{Introduction}

Microvascular changes are one of the most important common findings in collagen vascular diseases [1]. Such changes may lead to clinical features (e.g., Raynaud's phenomenon or digital ulcer) or structural abnormalities. Several methods have been developed to assess these changes, among which nailfold capillaroscopy (NFC) is the best.

Direct visualization of nailfold capillaries began in the early $19^{\text {th }}$ century [2], but the majorities of studies were conducted in 1990. The NFC device (Fig. 1) allows sequential magnifications (i.e. 100x, 200x, and 600x) which enable the detailed assessment of capillaries. A descriptive report of the quantitative microvascular changes includes normal capillaries, nonspecific abnormalities, and scleroderma patterns [3]. In 2013, these patterns were included in the European League Against Rheumatism (EULAR) and American College of Rheumatology (ACR) criteria for the diagnosis of systemic sclerosis, reflecting the significance and importance of NFC [4]. The most recent development in this field is the application of a new criterion, VEDOSS (Very Early Diagnosis of SSc), which includes (1) Raynaud's disease, (2) puffy swollen fingers turning into sclerodactyly, (3) abnormal capillaroscopy with scleroderma pattern, (4) positive anti-centromere (ACA), and (5) anti-topoisomerase (anti Scl-70) antibodies [5]. Therefore, it is essential for all practicing rheumatologists, dermatologists, and other specialists dealing with such patients (digital vascular complaints) to be familiar with this method.

\section{Indications}

The most important indication of NFC is Raynaud's phenomenon (RP), but other indications are:

1. Monitoring the transition from primary to secondary RP;

2. Early diagnosis of SSc;

3. Differential diagnosis of SSc-related conditions, such as localized SSc and eosinophilic fasciitis, which usually have a normal capillaroscopic pattern;

4. Detection of severe microangiopathy and prognostic evaluation in SSc;

5. Monitoring treatment and disease activity in dermatomyositis [6].

Normal NFC is an important criterion in differentiating between Primary and Secondary Raynaud's. In 2014, the following criteria were proposed and adopted in this regard: 


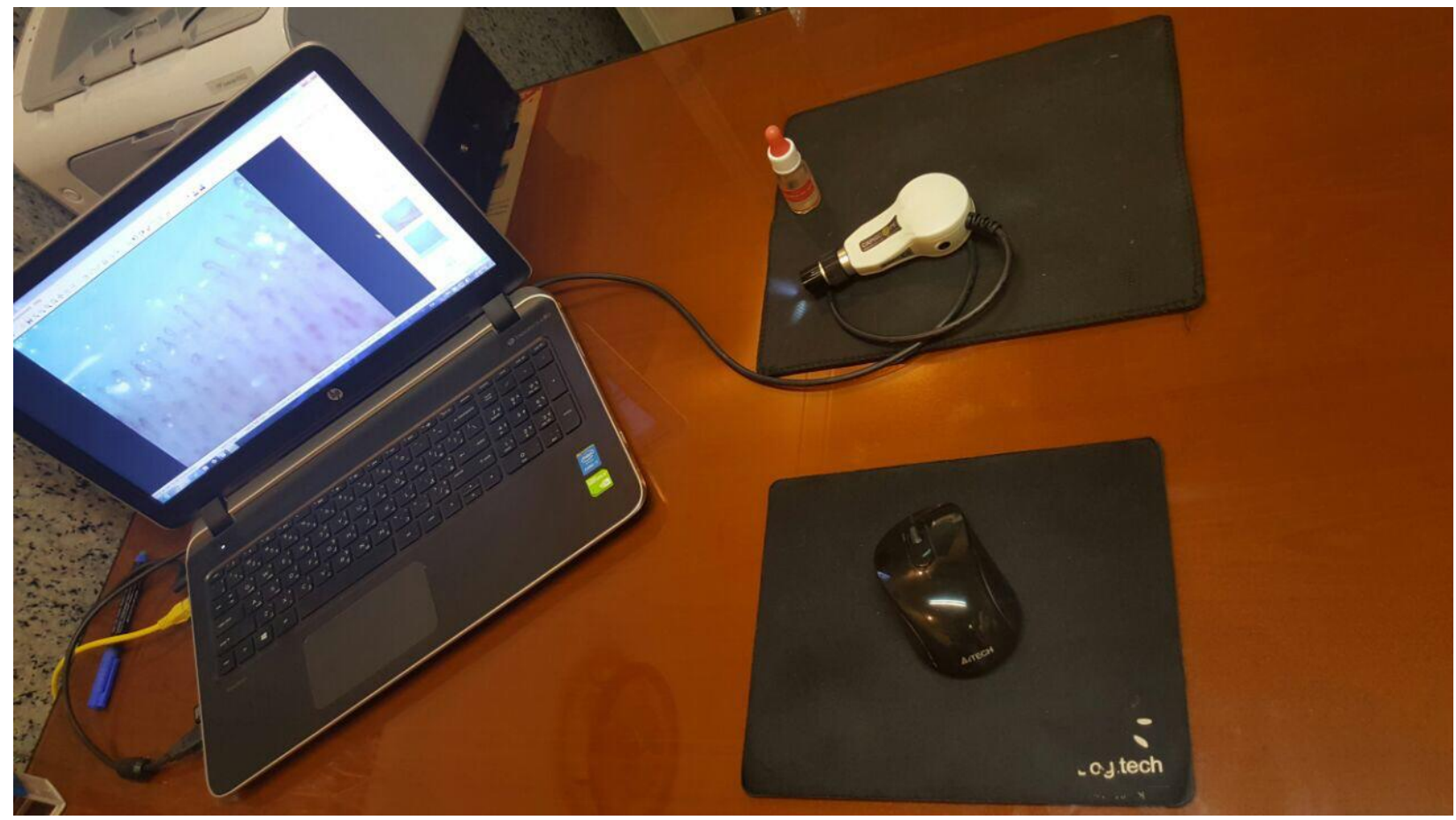

Fig. 1. Nailfold Capillaroscopy device

1. Presence of a clinical diagnosis of biphasic RP;

2. Normal NFC;

3. Physical examination with no findings suggestive of a secondary cause for RP (ulceration, gangrene, necrosis, sclerodactyly, calcinosis, or skin thickening);

4. No history of autoimmune rheumatic disease, and 5. Negative or low titer ANA [7].

\section{Preparation}

Use of the proper technique and preparation is essential. They are described below.

1. Patient preparation: Artificial nails and nail polish are contraindicated. Patients should have no history of recent (at least 2 weeks) trauma to the distal phalanges (including manicure), and the nail beds should appear normal with no evidence of recent or old infection, wound, etc. [8].

2. Environment preparation: Room temperature should be between $\left(22-25^{\circ} \mathrm{C}\right)$, and the patient should be present for at least 15 minutes before the examination so the nail fold capillary network can adapt to the room temperature [9].

\section{The procedure}

Nailfolds are prepared by rubbing on a thin layer of herbal oil, preferably cedar oil (olive oil and sesame oil can also be used). Emulsion oil used in microscopes is not recommended as it reduces the visual field [10].
All fingertips, except for the thumbs, should be studied. Thumbs often show irregularities in their capillary network due to repeated trauma in everyday tasks [11] (Fig. 2). The best fingers are often the $4^{\text {th }}$ (ring) and $5^{\text {th }}$ fingers, but it is better to study all eight fingers [12].

Three high quality pictures of each finger are taken from the medial and lateral corners of the nail bed and from the midpoint. These pictures increase the sensitivity of the diagnosis. A total of twenty-four images are recorded which is very important in scoring (quantitative assessment) and follow-up, but the average of the three readings for each nail is recorded in the table for the final report [13].

\section{How to read NFC}

Abnormal findings in the nail fold capillary network include [14]:

1. Architectural derangement

2. Capillary density changes

3. Megacapillary and enlarged loops

4. Microhemorrhages

5. Angiogenesis.

\section{Architectural derangement}

The shape, size, and orientation of the capillaries are taken into account to assess the architecture of the network. Normally, the capillaries are parallel to each other and to the axis of papilla, less than $20 \mu \mathrm{m}$, and are hairpin-like or U-shaped [15] (Fig. 3). 


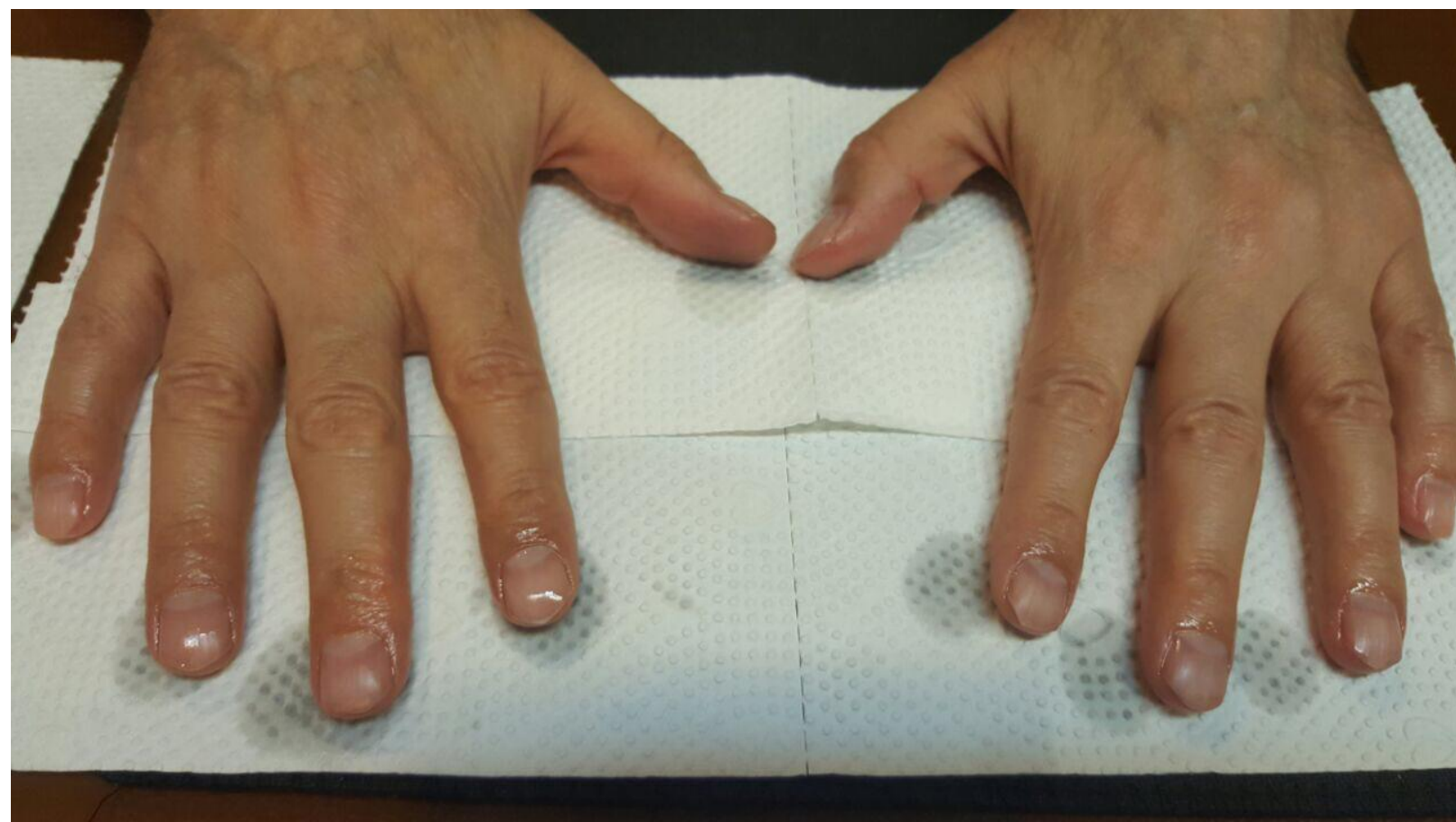

Fig. 2. Digital preparation for NFC

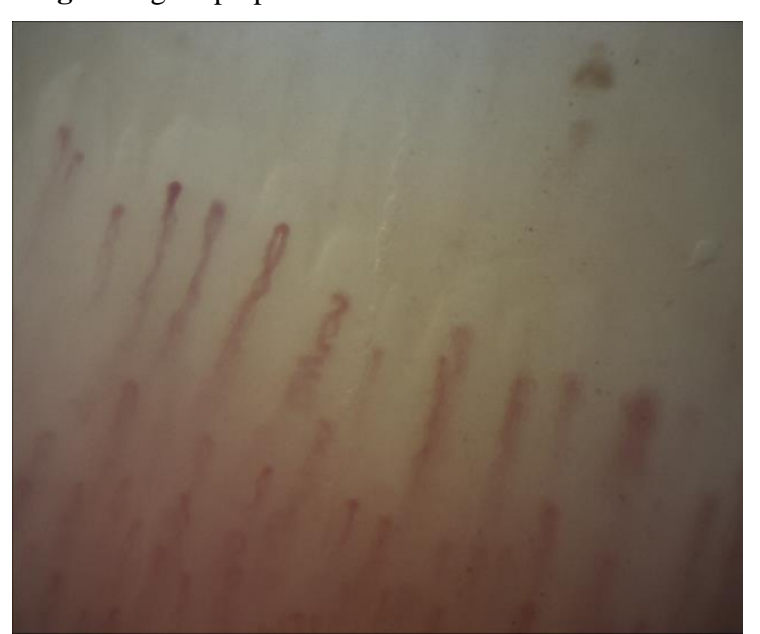

Fig. 3. Normal size, shape, and orientation of nailfold capillary network
Any changes in these three findings (orientation, size, or shape of capillaries) are categorized as architectural derangement and scored from 0-3 with 0 meaning no change. Changes below $33 \%$ of all capillaries are scored a 1; if 1/3-2/3 (33\%-66\%) of the capillaries are involved, they are scored 2 , and more than $2 / 3(66 \%)$ involvement of the capillaries are scored 3 [16]. Scoring is illustrated in Figure 4.

This scoring system is occasionally converted to a qualitative pattern: mild (score 1), moderate (score 2), severe (score 3), but for patient follow-up the quantitative approach (scoring system) is mandatory.

Severe architectural derangement (score 3 ) is seen only in SSc, but mild architectural derangement (score 1) may be seen in SLE, primary antiphospholipid syndrome, poly/dermatomyositis, rheumatoid arthritis, mixed connective tissue disease (MCTD), psoriatic arthritis, and diabetes mellitus $[17,18]$.

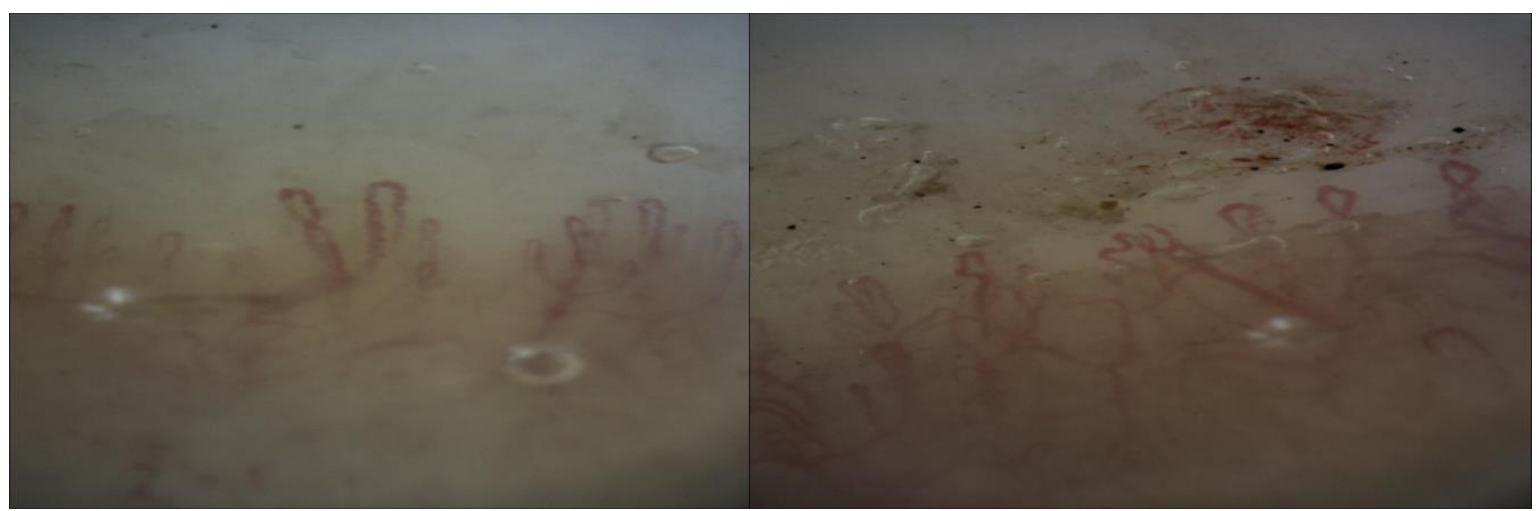

Fig. 4. Architectural derangement (left side, score 3; right side, score 2) 


\section{Capillary density changes}

Normal capillary density is 9-12 capillaries per millimeter. Changes are scored from 0 to 3 depending on the intensity of the capillary reduction. Nine or more capillaries per $\mathrm{mm}$ take the score of 0 , 6-9 capillaries/mm are scored 1; 3-6 capillaries/mm are scored 2, and less than 3 capillaries are scored 3 [19]. Samples are shown in Figure 5.

Moderate to severe changes (a score of 2-3) are the characteristic findings of SSc. A study showed that a reduction of capillary density below 6 capillaries/mm has a 92\% specificity for SSc [20]. The loss of capillaries leads to tissue hypoxia, the development of digital skin ulcers, and other clinical complications of SSc.

In patients with recent onset of RP, rapidly progressive capillary loss can represent the first dramatic capillaroscopic evidence of microvascular damage and development of severe SSc (1).

\section{Megacapillary and enlarged loops}

Capillaries more than 3-5 times the normal size (between 20-50 $\mu \mathrm{m}$ ) and 10 times the normal size (above $50 \mu \mathrm{m}$ ) are categorized as enlarged loops and megacapillaries, respectively. The scoring system of abnormalities is just like the one mentioned above. Changes below $33 \%$ of all capillaries are scored 1; if $1 / 3-2 / 3(33 \%-66 \%)$ of the capillaries are involved, they are scored 2; and more than $2 / 3(66 \%)$ involvement of the capillaries are scored 3 [21].

Enlarged loops may be the first sign of vessel wall damage. Homogeneously enlarged loops are the earliest and most striking feature of secondary RP and may be seen in CVD (17) and diabetes mellitus [21]. Figure 6 shows a few examples in this regard.

\section{Micro-hemorrhage}

This criterion is described as bleeding beyond the papillae (in the distal pulp). This finding is also scored from $0-3$ where 0 is no evidence of bleeding, 1 is only one line of bleeding, 2 is for 2 lines of bleeding, and 3 is for 3 or more lines of bleeding [22].

The appearance of microhemorrhages represents the 'bridge' between the presence of megacapillaries and the subsequent loss of capillaries. The shape of microhemorrhages may be totally variable. Different scores are shown in Figure 7.

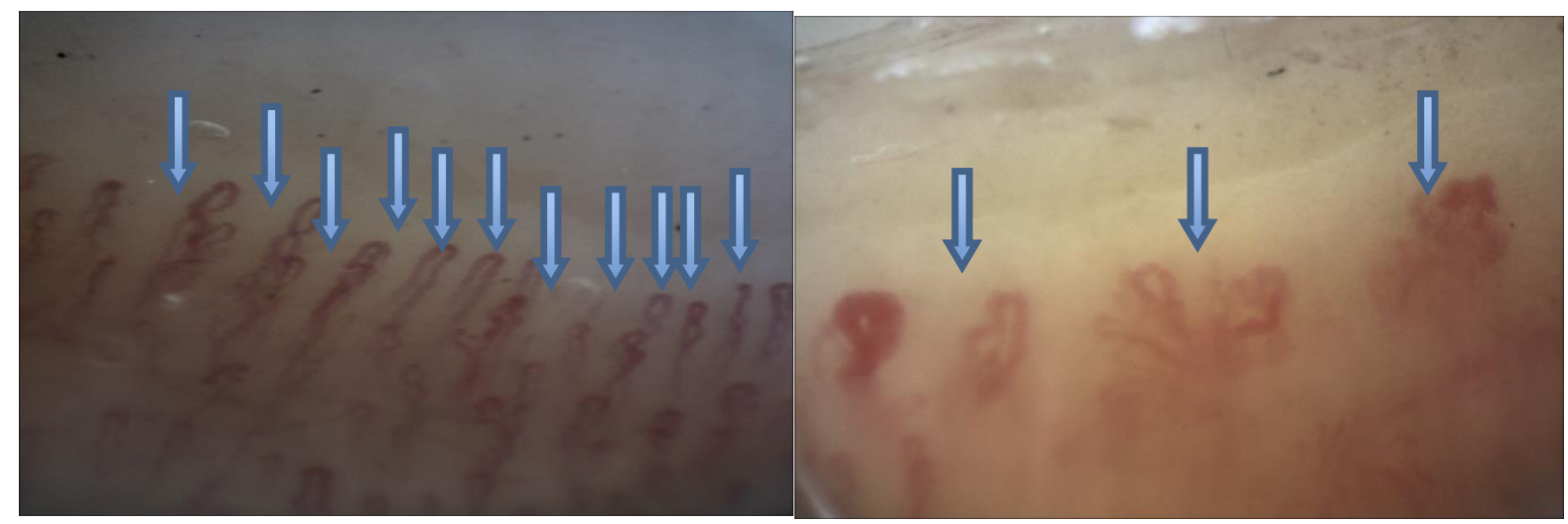

Fig. 5. Capillary density on the left $11 / \mathrm{mm}$, score 0 and on the right $3 / \mathrm{mm}$ with score 3

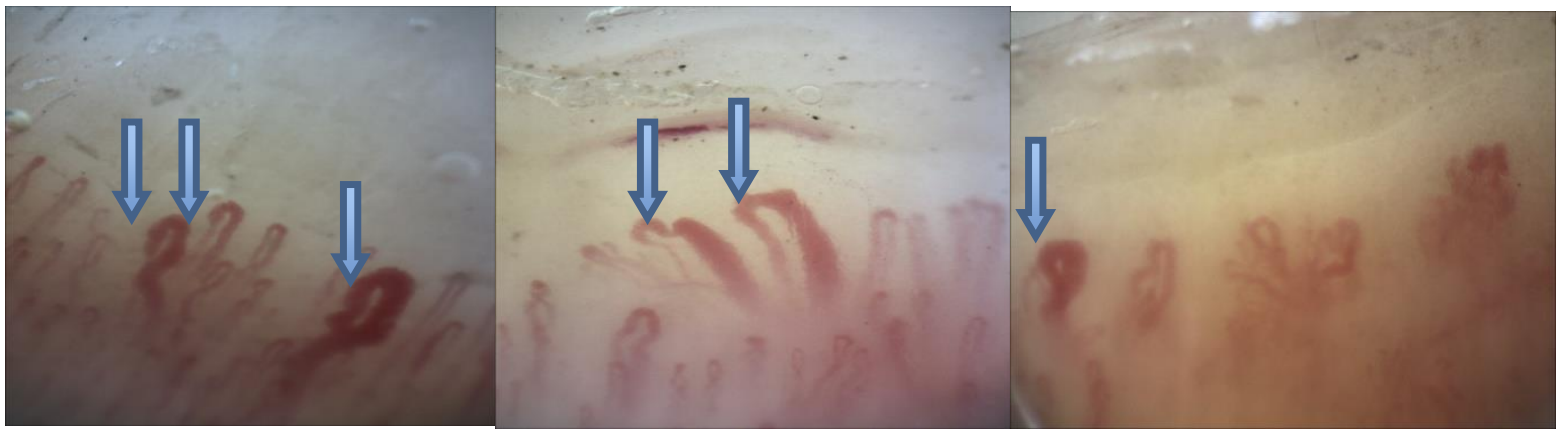

Fig. 6. Enlarged and megacapillary: scores 3, 2, and 1 are shown from left to right, respectively. 


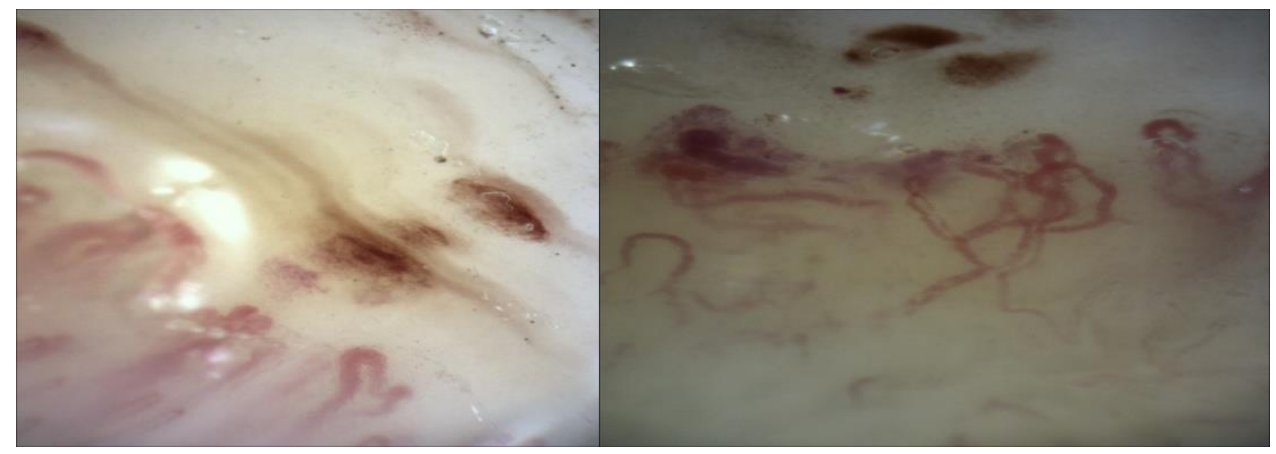

Fig. 7. Microhemorrhages scored 1 (left) and 2 (right)

\section{Angiogenesis}

The last finding is angiogenesis. It has been described as occurring in four types [9, 23]:

1. Mixed, branched and turn and twist capillaries (extremely tortuous);

2. Existence of four or more capillaries in one papilla;

3. Very enlarged loops;

4. Thin and connected capillaries branching of a single loop.

It is scored from 0-3. No change is scored as 0 , involvement of less than $1 / 3(33 \%)$ of capillaries is scored as 1 , involvement of between $(33 \%-66 \%)$ of capillaries is scored as 2 , and $2 / 3(66 \%)$ or more involvement is scored as $3[17,24]$.

Capillary loss leads to tissue hypoxia and local production of vessel growth factors (such as vascular endothelial growth factor or VEGF), which may stimulate the formation of new capillaries or angiogenesis.

Angiogenesis with low to moderate severity may be seen in SSc, dermatomyositis (especially the juvenile type), and MCTD.

Examples of angiogenesis are shown in Figure 8.

\section{How to interpret results}

Based on the abnormalities mentioned above, results are reported in three main categories [22, 25]:
1. Normal Capillaroscopy. When all five groups of findings are negative except for some degree of tortuosity, the term of "normal capillaroscopic findings" is applied. Tortuosity is relatively frequent in healthy subjects following microtrauma to the nailfold.

2. Nonspecific morphological abnormalities (NSMA). The presence of one abnormal finding, except severe capillary density loss, is categorized as "NSMA."

3. Scleroderma pattern. The existence of more than one abnormal finding in NFC is named "scleroderma pattern" or "scleroderma spectrum disorder (SSD)."

In a more recent study, microvascular alterations detected by NFC in patients with SSc were reclassified into three different subgroups as described below [8]:

- (Early): Very mild architectural derangement (0-1) No changes in capillary density (0-1)

Slightly enlarged loops and megacapillaries (1-2) Rare occurrence of microhemorrhage (1-2) Angiogenesis (1-2)

- (Active): Mild architectural derangement (1-2) Moderate changes in capillary density (1-2) Moderately enlarged loops and megacapillaries (2-3)

Moderate to severe microhemorrhages (2-3) Moderate angiogenesis (1-2)

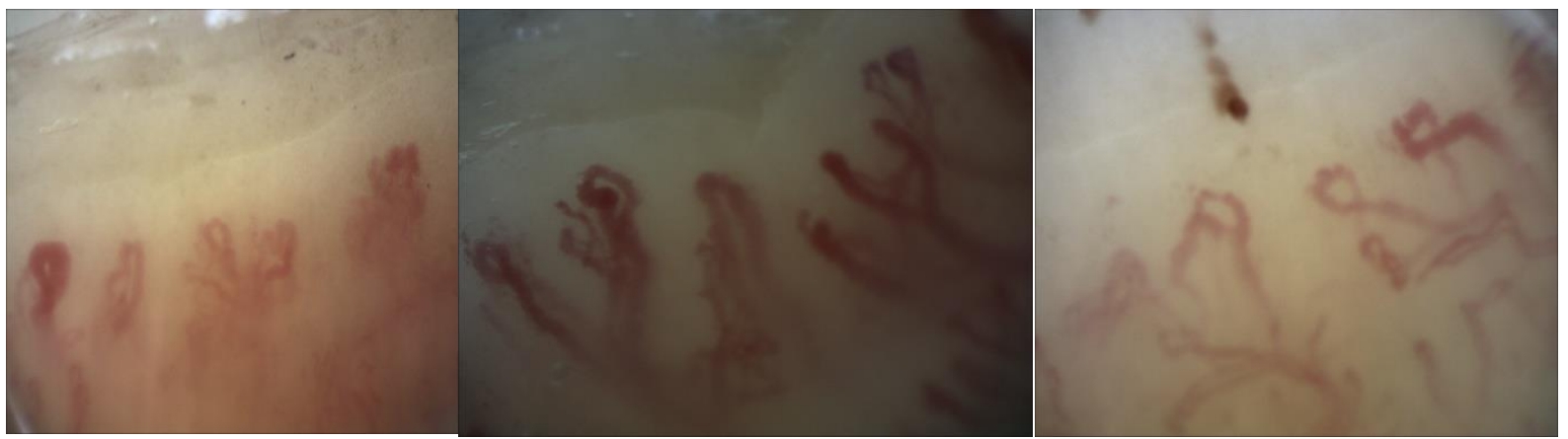

Fig. 8. Angiogenesis scores at left, middle, and right are 3 
Nail fold capillaroscopy reporting

- (Late): Severe architectural derangement (2-3) Severe changes in capillary density (2-3)

Enlarged loops or megacapillaries (1-3)

Microhemorrhage (1-3)

Angiogenesis (1-3)

A summary of the above is shown in Table 1.

Pavlov-Dolijanovic et al. proposed a classification method based on selected characteristics of disease progression [16]. The classification in this article is a combination of Pavlov-Dolijianovic et al. and Cutolo et al. Classifications with a quantitative scoring system are very helpful for monitoring and follow-up in SSc patients and may be used in CVD patients and cases suspicious of primary RP (Tables 2 and 3).

NFC is a simple non-invasive method of surveying microvascular disorders such as Raynaud's phenomenon. In patients with systemic sclerosis, NFC plays an important role in follow-up and predicting the prognosis of the disease. This method is also very informative in patients with known vascular complications such as diabetes and plays a documented role in disease management in order to improve future prognoses. In addition, interesting correlations are evident between NFC results and the clinical symptoms, disease severity, and laboratory findings.

Based on important findings (architectural derangement, capillary density, enlarged and giant capillary, microhemorrhage, and angiogenesis), the final report is categorized as normal, nonspecific morphological abnormalities, and scleroderma pattern. The scleroderma pattern is also divided into three types: early, active, and late.

The NFC interpretation with a scoring system (quantitative method) should be adopted if the results are to be used for the diagnosis and follow-up of patients with systemic sclerosis.

Table 1. Scoring in different patterns of involvement in NFC

\begin{tabular}{lccccc}
\hline & $\begin{array}{c}\text { Architectural } \\
\text { derangement }\end{array}$ & $\begin{array}{c}\text { Capillary } \\
\text { density } \\
\text { changes }\end{array}$ & $\begin{array}{c}\text { Enlarged loops } \\
\text { and } \\
\text { megacapillaries }\end{array}$ & Microhemorrhages & Angiogenesis \\
\hline Normal & 0 & 0 & 0 & 0 & 0 \\
$\begin{array}{l}\text { Non-specific morphological } \\
\text { abnormalities (NSMA) }\end{array}$ & $0-1$ & 0 & $0-1$ & $0-1$ & $0-1$ \\
Scleroderma pattern (Early) & $1-2$ & $0-1$ & $1-2$ & $1-2$ & $1-2$ \\
Scleroderma pattern (Active) & $2-3$ & $1-2$ & $1-2$ & $1-2$ & $1-2$ \\
Scleroderma pattern (Late) & $2-3$ & 3 & $2-3$ & $1-3$ & $2-3$ \\
\hline
\end{tabular}

Table 2. NFC sample report (quantitative scoring) in both hands without thumbs.

\begin{tabular}{lllll|lllll}
\hline \multicolumn{1}{c}{ Score: Left hand fingers } & $\mathbf{2}^{\text {nd }}$ & $\mathbf{3}^{\text {rd }}$ & $\mathbf{4}^{\text {th }}$ & $\mathbf{5}^{\text {th }}$ & Score: Right hand fingers & $\mathbf{5}^{\text {th }}$ & $\mathbf{4}^{\text {th }}$ & $\mathbf{3}^{\text {rd }}$ & $\mathbf{2}^{\text {nd }}$ \\
\hline Irregularly enlarged capillary & 2 & 3 & 3 & 2 & Irregularly enlarged capillary & 2 & 2 & 1 & 3 \\
Giant capillary & 2 & 1 & 0 & 1 & Giant capillary & 2 & 1 & 2 & 1 \\
Microhemorrhages & 1 & 0 & 1 & 1 & Microhemorrhages & 2 & 1 & 1 & 1 \\
Capillary number & 2 & 2 & 2 & 2 & Capillary number & 1 & 2 & 1 & 2 \\
Capillary ramifications & 2 & 2 & 3 & 1 & Capillary ramifications & 0 & 0 & 0 & 3 \\
Capillary array disorganization & 2 & 2 & 3 & 0 & Capillary array disorganization & 0 & 0 & 0 & 2 \\
\hline
\end{tabular}

Table 3. Scoring and evolution scale developed by Cutolo

\begin{tabular}{ll}
\hline Example of score calculation in patients with above findings & Score \\
\hline Irregularly enlarged capillary & $(2+2+1+3+2+3+3+2) / 8=2.25$ \\
Giant capillary & $(2+1+2+1+2+1+0+1) / 8=1.25$ \\
Microhemorrhages & $(2+1+1+1+1+0+1+1) / 8=1$ \\
Capillary number & $(1+2+1+2+2+2+2+2) / 8=1.75$ \\
Capillary ramifications & $(0+0+0+3+2+2+3+1) / 8=1.37$ \\
Capillary array disorganization & $(0+0+0+2+2+2+3+0) / 8=1.12$ \\
\hline
\end{tabular}




\section{References}

1. Cutolo M, Grassi W, Matucci Cerinic M. Raynaud's phenomenon and the role of capillaroscopy. Arthritis \& rheumatism. 2003; 48(11): 3023-30.doi: 10.1002/art.11310.

2. Raynaud M. De l'asphyxie locale et de la gangrene symetrique des extremites: Rignoux; 1862.

3. van den Hoogen F, Khanna D, Fransen J, Johnson SR, Baron M, Tyndall A, Matucci-Cerinic M, Naden RP, Medsger TA Jr, Carreira PE, Riemekasten G, Clements PJ, Denton CP, Distler O, Allanore Y, Furst DE, Gabrielli A, Mayes MD, van Laar JM, Seibold JR, Czirjak L, Steen VD, Inanc M, KowalBielecka O, Müller-Ladner U, Valentini G, Veale DJ, Vonk MC, Walker UA, Chung L, Collier DH, Csuka ME, Fessler BJ, Guiducci S, Herrick A, Hsu VM, Jimenez S, Kahaleh B, Merkel PA, Sierakowski S, Silver RM, Simms RW, Varga J, Pope JE. 2013 classification criteria for systemic sclerosis: an American College of Rheumatology/ European League against Rheumatism collaborative initiative. Arthritis Rheum 2013 Nov; 65(11): 2737-47. doi: 10.1002/art 38098.

4. Smith V, Pizzorni C, De Keyser F, Decuman S, Van Praet JT, Deschepper E, et al. Reliability of the qualitative and semiquantitative nailfold videocapillaroscopy assessment in a systemic sclerosis cohort: a two-centre study. Annals of the rheumatic diseases. 2010; 69(6): 1092-6. doi: 10.1136/ard.2009.115568.

5. Avouac J, Fransen J, Walker U, Riccieri V, Smith V, Muller C, et al. Preliminary criteria for the very early diagnosis of systemic sclerosis: results of a Delphi Consensus Study from EULAR Scleroderma Trials and Research Group. Annals of the rheumatic diseases. 2011; 70(3): 476-81. doi: 10.1136/ard. 2010.136929.

6. Souza EJdR, Kayser C. Nailfold capillaroscopy: relevance to the practice of rheumatology.

Revista brasileira de

reumatologia. 2015; 55(3): 264-

71. doi: $10.1016 /$ j.rbre.2014.09. 005.

7. Maverakis E, Patel F, Kronenberg DG, Chung L, Fiorentino D, Allanore Y, et al. International consensus criteria for the diagnosis of Raynaud's phenomenon. Journal of autoimmunity. 2014; 48:60-5. doi: 10.1016/j.jaut.2014.01.020.

8. Cutolo M, Sulli A, Pizzorni C, Accardo S. Nailfold videocapillaroscopy assessment of microvascular damage in systemic sclerosis. The Journal of Rheumatology. 2000; 27(1): 155-60.

9. Cutolo M, Sulli A, Secchi ME, Olivieri M, Pizzorni C. The contribution of capillaroscopy to the differential diagnosis of connective autoimmune diseases. Best practice \& research Clinical rheumatology. 2007; 21(6): 1093-108. doi: 10.1016/j.berh. 2007.10.001.

10. Dolezalova P, Young S, Bacon $P$, Southwood T. Nailfold capillary microscopy in healthy children and in childhood rheumatic diseases: a prospective single blind observational study. Annals of the rheumatic diseases. 2003; 62(5): 444-9. doi: 10.1136/ard. 62.5.444.

11. De Angelis R, Cutolo $\mathrm{M}$, Gutierrez M, Bertolazzi C, Salaffi F, Grassi W. Different microvascular involvement in dermatomyositis and systemic sclerosis. A preliminary study by a tight videocapillaroscopic assessment. Clin Exp Rheumatol 2012 Mar-Apr; 30(2 Suppl 71): S67-70. doi:10.1053/ sarh.2001.20269.

12. Andrade LE, Gabriel Júnior A, Assad RL, Ferrari AJ, Atra E. Panoramic nailfold capillaroscopy: a new reading method and normal range. Semin Arthritis Rheum 1990 Aug; 20(1): 21-31. doi: 10.1016/0049-0172(90)90091-s.

13. Silver RM, Maricq HR. Childhood dermatomyositis: serial microvascular studies. Pediatrics. 1989; 83(2): 278-83.

14. Maricq HR. Widefield capillary microscopy. Technique and rating scale for abnormalities seen in scleroderma and related disorders. Arthritis \& Rheumatism. 1981; 24(9): 1159-65. doi: 10.1002/art. 1780240907.

15. Maricq HR. Comparison of quantitative and semiquantitative estimates of nailfold capillary abnormalities in scleroderma spectrum disorders. Microvascular research. 1986; 32(2): 271-6. doi: 10.1016/ 0026-2862(86)90062-2.

16. Gayraud M. Raynaud's phenomenon. Joint Bone Spine. 2007; 74(1): e1-e8. doi: 10.1016/j.jbspin.2006.07.002.

17. Cortes S, Cutolo M Capillarosecopic patterns in rheumatic diseases. Acta Reumatol Port. 2007 Jan-Mar; 32(1): 29-36.

18. Rajaei A, Dehghan P, Farahani $Z$. Nailfold capillaroscopy findings in diabetic patients (a pilot cross-sectional study). Open Journal of Pathology. 2015; 5(02): 65-72 doi: 10.4236/ ojpathology.2015.52010.

19. Sulli A, Secchi ME, Pizzorni C, Cutolo M. Scoring the nailfold microvascular changes during the capillaroscopic analysis in systemic sclerosis patients. Annals of the rheumatic diseases. 2008; 67(6): 885-7. doi: 10.1136/ard.2007.079756.

20. Houtman P, Kallenberg C, Fidler V, Wouda A. Diagnostic significance of nailfold capillary patterns in patients with Raynaud's phenomenon. An analysis of patterns discriminating patients with and without connective tissue disease. The Journal of rheumatology. 1986; 13(3): 556-63.

21. Ingegnoli $\mathrm{F}$, Zeni $\mathrm{S}$, Gerloni V, Fantini F. Capillaroscopic observations in childhood rheumatic diseases and healthy controls. Clin Exp Rheumatol 2005 Nov-Dec; 23(6): 905-11. doi: 10.1097/01.rhu.00001911 93. 93720.95 
Nail fold capillaroscopy reporting

22. Pavlov-Dolijanovic

$\mathrm{S}$, Damjanov NS, Stojanovic RM, Vujasinovic Stupar NZ, Stanisavljevic DM. Scleroderma pattern of nailfold capillary changes as predictive value for the development of a connective tissue disease: a follow-up study of 3,029 patients with primary Raynaud's phenomenon. Rheumatol Int 2012 Oct;
32(10): 3039-45. doi: 10.1007/s00296-011-2109-2.

23. Grassi W, De Angelis R. Capillaroscopy: questions and answers. Clinical rheumatology. 2007; 26(12): 2009-16. doi: 10.1007/s10067007-0681-3.

24. Herrick A. Diagnosis and management of scleroderma peripheral vascular disease.
Rheumatic Disease Clinics of North America. 2008; 34(1): 89-114. doi: 10.1016/j.rdc.2007. 11.006.

25. Cutolo M, Pizzorni C, Secchi ME, Sulli A. Capillaroscopy. Best practice \& research Clinical rheumatology. 2008; 22(6): 1093-108. doi: 10.1016/j.berh.2008.09.001. 